\title{
Evaluation of Cases of Intracerebral Hemorrhage - A Clinical Study
}

\author{
Praveen $\mathrm{K}^{1}$, Shiby T G ${ }^{2}$ \\ ${ }^{1}$ MBBS, MS, MCh (Neurosurgery), DNB, Assistant professor, Department of Neurosurgery, MES Medical College, Perintalmanna \& Consultant \\ Neurosurgeon, KIMS ALSHIFA, perintalmanna, ${ }^{2}$ MBBS, DPMR, MD, DNB (PM\&R), Associate Professor, Department of physical medicine and \\ rehabilitation, Government Medical College, Thrissur, Kerala
}

\section{Abstract}

Background: Intracerebral hemorrhage is bleeding into the brain parenchyma. The present study was to assess cases of intracerebral hemorrhage. Subjects and Methods: The present study was conducted on 74 cases of intracerebral hemorrhage of both genders. Patients were examined clinically and MRI was done in all patients. GCS score was recorded. Results: Out of 74 patients, males were 48 and females were 26. Maximum cases were seen in age group 60-80 years (47) followed by 40-60 years (23) and 20-40 years (4). The difference was significant $(\mathrm{P}<0.05)$. Patients had weakness in 48 , altered sensorium in 72 , speech disturbance in 65 , vomiting in 35 , headache in 61 and convulsions in 32. The difference was significant $(\mathrm{P}<0.05)$. GCS score 3-4 was seen in 4 with mortality of 3, 5-8 was seen in 10 with mortality of $1,9-13$ was seen in 22 with mortality of 1 and $14-15$ was seen in 38 . The difference was significant $(\mathrm{P}<0.05)$. Conclusion: Maximum mortality was seen in patients with GCS score between 3-4 and maximum cases were in age group 60-80 years.

Keywords: Glasgow Coma Scale, Intracerebral hemorrhage, Sensorium.

Corresponding Author: Dr. Shiby T G, MBBS, DPMR, MD, DNB (PM\&R), Associate Professor, Department of physical medicine and rehabilitation, Government Medical College, Thrissur, Kerala.

Received: December 2019

Accepted: December 2019

\section{Introduction}

Spontaneous Brain hemorrhage accounts for about $10 \%$ of all strokes and is associated with a high morbidity and mortality rate. While the incidence of stroke due to occlusive cerebrovascular disease has declined the incidence of intracerebral hemorrhage has remained relatively stable. The syndromes that result from brain hemorrhage are sufficiently characterized to permit their clinical recognition in many patients. ${ }^{[1]}$ The World Health Organization (WHO) estimates that 15 million patients worldwide suffer from stroke annually. Approximately one third of these cases die, one third are left disabled and one third have a good outcome. High blood pressure is a contributing factor in more than 12.7 million strokes annually worldwide. Incidence is greater among the elderly and those of African and Asian decent. ${ }^{[2]}$ In hemorrhagic stroke, bleeding can occur within the cerebral parenchyma or within the meninges. Intracerebral hemorrhage (ICH) is defined as bleeding into the brain parenchyma. The current review excluded epidural hematoma, subdural hematoma and subarachnoid haemorrhage but includes intraventricular hemorrhage. Prognoses of hemorrhagic strokes depend on the initial clinical presentation, rapidity of diagnosis and time to initiation of intervention. ${ }^{[3]}$

Hypertensive brain hemorrhage tends to occur in specific sites: putamen, thalamus, cerebellum and pons. Lobar hemorrhage may be related to hypertension but it can also occur in association with normal blood pressure and no radiographic evidence of a specified etiologic factor. ${ }^{[4]}$ Spontaneous nonhypertensive brain hemorrhage may be associated with aneurysm, arteriovenous malformation $(\mathrm{AVM})$, primary or metastatic brain tumor infarction, anticoagulation, diseases associated with clotting disorders such as leukemia, thrombotic thrombocytopenic purpura, sickle cell disease and cerebral arteritis such as occurs with collagen vascular disease, amyloid angiopathy and methamphetamine abuse. ${ }^{[5]}$ The present study was to assess cases of intracerebral hemorrhage.

\section{Subjects and Methods}

The present study was conducted in the department of Neurology. It is a retrospective study. It comprised of 74 cases of intracerebral hemorrhage of both genders.. Ethical clearance was obtained prior to the study. General data such as name, age, gender etc. was recorded. Patients details were collected from the case records kept in the hospital. MRI or CT was done in all patients. GCS score was recorded. Survival and death were assessed as good and poor outcome respectively. Results thus obtained were subjected to statistical analysis. P value less than 0.05 was considered significant. 


\section{Results}

\section{Table 1: Distribution of patients}

\begin{tabular}{|l|l|l|}
\hline Gender & Males & Females \\
\hline Number & 48 & 26 \\
\hline
\end{tabular}

[Table-1] shows that out of 74 patients, males were 48 and females were 26 .

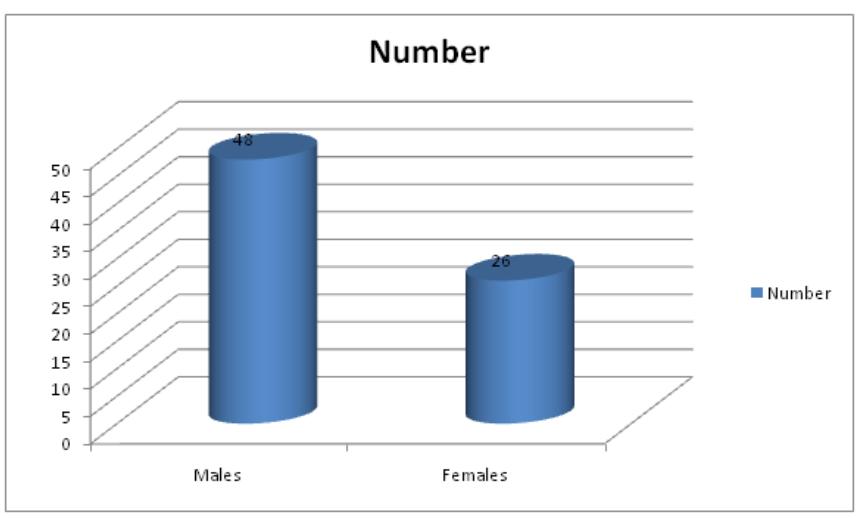

Graph 1: Distribution of patients

Table 2: Age wise distribution of cases

\begin{tabular}{|l|l|l|}
\hline Age group (Years) & Number & P value \\
\hline $20-40$ & 4 & \multirow{2}{*}{0.01} \\
\hline $40-60$ & 23 & \\
\hline $60-80$ & 47 & \\
\hline
\end{tabular}

[Table 2], Graph 2 shows that maximum cases were seen in age group 60-80 years (47) followed by 40-60 years (23) and 20-40 years $(4)$. The difference was significant $(\mathrm{P}<0.05)$.

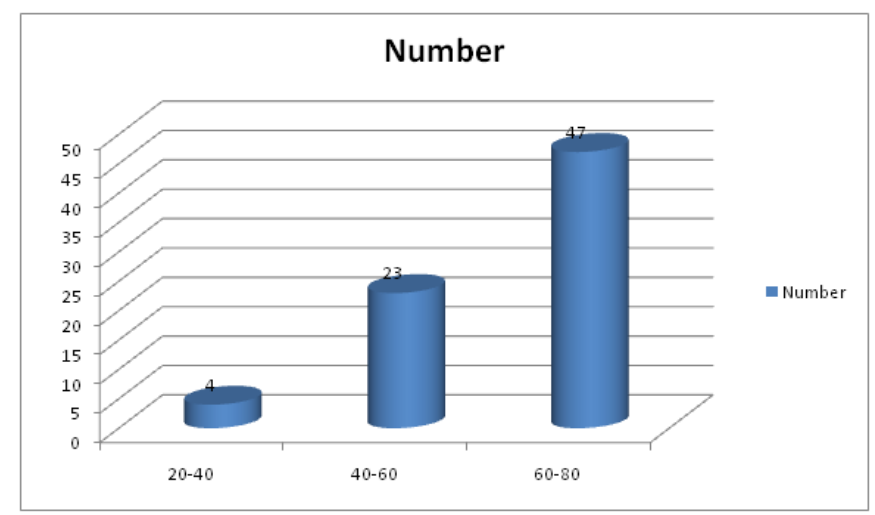

Graph 2: Age wise distribution of cases

Table 3: Spectrum of clinical presentation

\begin{tabular}{|l|l|l|}
\hline Clinical presentation & Number & \multirow{2}{*}{ P value } \\
\hline Weakness & 48 & \\
\cline { 1 - 2 } Altered sensorium & 72 & \\
\cline { 1 - 2 } Speech disturbance & 65 & \\
\hline Vomiting & 35 & \\
\cline { 1 - 2 } Headache & 61 & \\
\cline { 1 - 2 } Convulsions & 32 & \\
\hline
\end{tabular}

[Table-3], Graph-3 shows that patients had weakness in 48, altered sensorium in 72 , speech disturbance in 65 , vomiting in 35, headache in 61 and convulsions in 32 . The difference was significant $(\mathrm{P}<0.05)$.

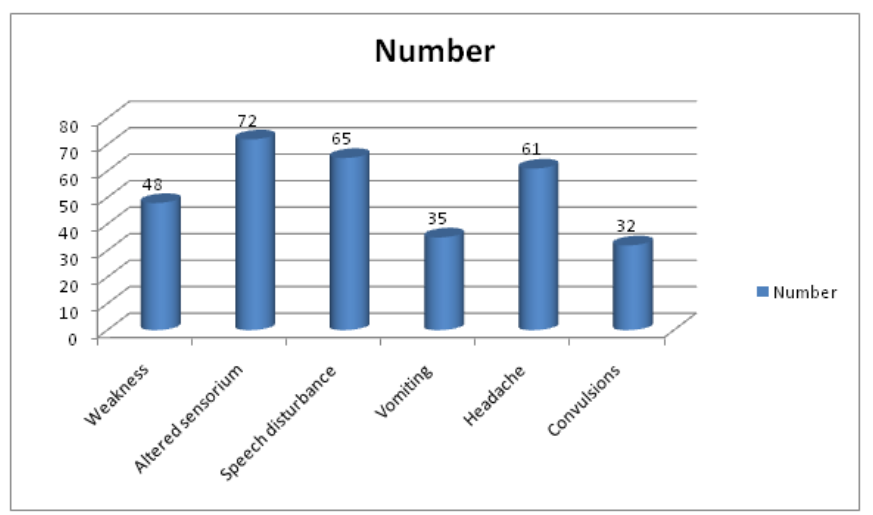

Graph 3: Spectrum of clinical presentation

Table 4: Glasgow Coma Scale (GCS) and mortality

\begin{tabular}{|l|l|l|l|}
\hline GCS score & Number & Mortality & P value \\
\hline $3-4$ & 4 & 3 & \multirow{2}{*}{0.01} \\
\hline $5-8$ & 10 & 1 & \\
\hline $9-13$ & 22 & 1 & \\
\hline $14-15$ & 38 & 0 & \\
\hline
\end{tabular}

[Table-4], Graph-4 shows that GCS score 3-4 was seen in 4 with mortality of $3,5-8$ was seen in 10 with mortality of $1,9-13$ was seen in 22 with mortality of 1 and 14-15 was seen in 38. The difference was significant $(\mathrm{P}<0.05)$.

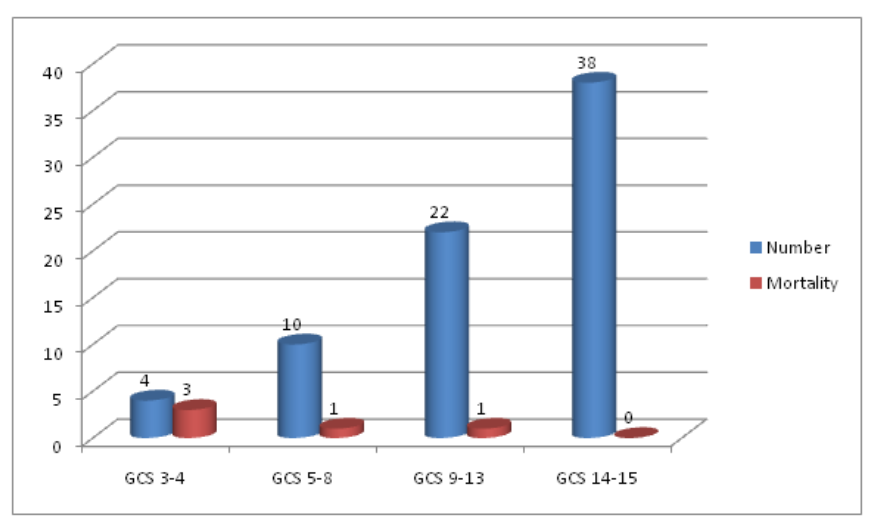

Graph 4: Glasgow Coma Scale (GCS) and mortality

\section{Discussion}

In hypertensive hemorrhage, the most common sources of bleeding are the small penetrating arteries in the base of the brain and the paramedian branches of the basilar artery. Though these vessels normally can withstand extremely high pressure without rupture, pathological changes lead to weakness. ${ }^{[6]}$ It has been suggested that microaneurysms could be the cause of the hemorrhage but careful histological studies indicate that fibrinoid necrosis is usually the etiology of the weakness in the arterial wall. ${ }^{[7]}$ The final triggering mechanism for the rupture is not known, although it has been speculated that a sudden increase in blood pressure coincident with factors such as exertion or emotion stress may excede the tolerance of the vessel wall. This notion is supported by the finding that the setting for the hemorrhage is usually during activity and infrequently during sleep. ${ }^{[8]}$

Modifiable risk factors for ICH include hypertension, anticoagulant therapy, thrombolytic therapy, high alcohol intake, 
previous history of stroke, and illicit drug use (particularly cocaine). Hypertension is by far the most common cause of hemorrhagic stroke, accounting for up to $60 \%$ of all ICH cases. ${ }^{[9]}$ Moreover, approximately two thirds of patients with $\mathrm{ICH}$ have a history of hypertension. Hypertensive ICH results from tiny aneurysms that rupture and result in intracranial hemorrhage. Anticoagulation therapy causes a seven to tenfold increase in risk for hemorrhagic stroke. ${ }^{[10]}$ The present study was to assess cases of intracerebral hemorrhage.

In this study, out of 74 patients, males were 48 and females were 26. Maximum cases were seen in age group 60-80 years (47) followed by 40-60 years (23) and 20-40 years (4). Juvela et $\mathrm{al}^{[11]}$ found that all patients $(\mathrm{n}=211)$, aged more than 12 years, diagnosed with ICH (based on CT scan/MRI) were studied. ICH was more common in $>60 \mathrm{yr}$ age group $(52.13 \%)$. Mean Age $( \pm$ SD) was $62.04( \pm 15.16)$. M: F ratio is $1.15: 1$. Its incidence increased during the winter season $(53.55 \%)$ from the months of November to February and early morning hours $(61.14 \%)$. Weakness $(69.67 \%)$ and loss of consciousness (LOC) /altered sensorium (59.72\%) were the two most common presenting complaints on admission. In-Hospital mortality was $87(41.23 \%)$ with maximum mortality occurring within 72 hours.

We found that patients had weakness in 48, altered sensorium in 72, speech disturbance in 65, vomiting in 35 , headache in 61 and convulsions in 32. GCS score 3-4 was seen in 4 with mortality of $3,5-8$ was seen in 10 with mortality of 1, 9-13 was seen in 22 with mortality of 1 and 14-15 was seen in 38. Kase et $\mathrm{al}^{12}$ found that out of 87 patients, 49 patients $(63 \%)$ were male and 38 patients $(37 \%)$ were females, male to female ratio was 1.2:0.8. Nearly $42 \%$ patient had systolic blood pressure with in normal range; however, in almost $50 \%$ of the cases, the systolic blood pressure at the time of admission was more than $140 \mathrm{mmHg}$. mRS was assessed for the patients at the time of admission, $39 \%$ patients had slight disability, $15 \%$ patients had moderate disability, $11 \%$ patients had moderately severe disability, and $33 \%$ patients had severe disability. Mortality was relatively higher in patients who had admission systolic blood pressure more than $140 \mathrm{mmHg}$ (51\% vs. 43\%). mRS was assessed for the patients at the time of discharge after completion surgery and the severity of scale. They found that hypertension was found to be most common comorbid illness followed by smoking, alcohol intake, and diabetes mellitus.

\section{Conclusion}

Authors found that maximum mortality was seen in patients with GCS score between 3-4 and maximum cases were in age group 60-80 years.

\section{References}

1. Becker KJ, Baxter AB, Bybee HM, et al. Extravasation of radiographic contrast is an independent predictor of death in primary intracerebral hemorrhage. Stroke. 1999;30:2025-32.

2. Ohwaki K, Yano E, Nagashima H, et al. Blood pressure management in acute intracerebral hemorrhage: relationship between elevated blood pressure and hematoma enlargement. Stroke. 2004; 35:1364-7.

3. Toyoda K, Okada Y, Minematsu K, et al. Antiplatelet therapy contributes to acute deterioration of intracerebral hemorrhage. Neurology. 2005; 65: 1000-04.

4. Yasaka M, Minematsu K, Naritomi H, et al. Predisposing factors for enlargement of intracerebral hemorrhage in patients treated with warfarin. Thromb Haemost. 2003; 89: 278-83.

5. Flibotte JJ, Hagan N, O’Donnell J, et al. Warfarin, hematoma expansion, and outcome of intracerebral hemorrhage. Neurology. 2004; 63: 1059-64.

6. Elliott J, Smith M. The acute management of intracerebral hemorrhage: a clinical review. Anesth Analg. 2010; 110(5): 1419-27.

7. Rincon F, Mayer SA. Clinical review: Critical care management of spontaneous intracerebral hemorrhage. Critical Care. 2008; 12: 237.

8. Mayer, SA.; Chong, JY. Critical care management of increased intracranial pressure. Journal of Intensive Care Medicine. 2002;17 (2):55-67.

9. Sahni R, Weinberger J. Management of intracerebral hemorrhage. Vasc Health Risk Manag. 2007; 3(5): 701-9.

10. Shah DC, Babanagar SK. Assessment of Importance of CT scans in evaluation of Cerebrovascular Accidents. J Adv Med Dent Scie Res 2017;5(12):29-31.

11. Juvela S, Hillborn M, Palomaki H. Risk factors for spontaneous intracerebral hemorrhage.Stroke 1995; 26:1558-64.

12. Kase, K. S. Vascular diseases of the nervous system: Intracranial hemorrhage. In Daroff: Bradley's Neurology in Clinical Practice 6 ed. Philadelphia, PA: Elesvier Inc; 2012; p. 1054-69.

Copyright: (C) the author(s), 2019. It is an open-access article distributed under the terms of the Creative Commons Attribution License (CC BY 4.0), which permits authors to retain ownership of the copyright for their content, and allow anyone to download, reuse, reprint, modify, distribute and/or copy the content as long as the original authors and source are cited.

How to cite this article: Praveen K, Shiby TG. Evaluation of Cases of Intracerebral Hemorrhage - A Clinical Study. Acad. J Surg. 2019;2(2):45-47.

DOI: dx.doi.org/10.21276/ajs.2019.2.2.12

Source of Support: Nil, Conflict of Interest: None declared. 